\title{
Erosive esophagitis and symptoms of gastroesophageal reflux disease in patients with morbid obesity with and without type 2 diabetes. A cross sectional study.
}

\section{Background:}

Type 2 diabetes (T2DM) is associated with gastroesophageal reflux disease (GERD) in the general population, but the relationship between these conditions in candidates for bariatric surgery is uncertain. We compared the prevalence of GERD and the association between GERD-symptoms and esophagitis among bariatric candidates with and without T2DM.

Methods: Cross sectional study of baseline data from the Oseberg study in Norway. Both groups underwent gastroduodenoscopy and completed validated questionnaires:

Gastrointestinal Symptom Rating Scale and Gastro Esophageal Reflux Disease Questionnaire. Participants with T2DM underwent 24-hour pH-metry.

Results: A total of 124 patients with T2DM, 81 women, mean (SD) age 48.6 (9.4) years and BMI $42.3(5.5) \mathrm{kg} / \mathrm{m}^{2}$, and 64 patients without T2DM, 46 women, age 43.0 (11.0) years and BMI $43.0(5.0) \mathrm{kg} / \mathrm{m}^{2}$, were included. The proportions of patients reporting GERD-symptoms were low $(<29 \%)$ and did not differ significantly between groups, while the proportions of patients with esophagitis were high both in the T2DM and non-T2DM group, 58\% vs 47\%, $p=0.16$. The majority of patients with esophagitis did not have GERD-symptoms (68\%-80\%). Further, 55\% of the patients with T2DM had pathologic acid reflux. Among these, $71 \%$ also had erosive esophagitis, whereof $67 \%$ were asymptomatic.

Conclusions: The prevalence of GERD was similar in bariatric patients with or without T2DM, and the proportion of patients with asymptomatic GERD was high independent of the presence or absence of T2DM. Accordingly, GERD may be underdiagnosed in patients not undergoing a preoperative endoscopy or acid reflux assessment.

Trial registration: Clinical Trials.gov number NCT01778738. 


\section{Keywords}

Gastroesophageal Reflux Disease (GERD). Erosive esophagitis. Heartburn. Acid regurgitation. Acid reflux. Type 2 diabetes mellitus. Obesity. Bariatric surgery. 


\section{Introduction}

Gastroesophageal reflux disease (GERD) is common with a worldwide prevalence of 8-33\% (1-4) and GERD symptoms have been reported in up to $73 \%$ of bariatric surgery candidates $(5,6)$. GERD develops when the reflux of acid gastric content causes troublesome symptoms and/or mucosal damage (7) and is associated with increased risk of esophageal strictures, Barrett's esophagus and esophageal adenocarcinoma (8).

Obesity is an independent risk factor for GERD (9), partly due to obesity related hiatal hernia $(10,11)$, decreased lower esophageal sphincter (LES) resting pressure (9), and higher intragastric pressure $(10,12)$. Type 2 diabetes mellitus (T2DM) is associated with GERD independent of body weight $(2,13)$.

Patients with T2DM may be more susceptible to both GERD symptoms and asymptomatic erosive esophagitis $(14,15)$. However, whether patients with T2DM scheduled for bariatric surgery have a higher prevalence of GERD than those without T2DM is uncertain. Further, it is well known that GERD symptoms and endoscopic findings are weakly correlated (16-19), but the relationship between esophagitis and GERD symptoms in patients with or without T2DM has not been well investigated $(10,20)$. In addition, few previous studies have assessed the association between esophageal acid exposure and reflux symptoms or erosive esophagitis in subjects with severe obesity $(10,21,22)$.

We aimed, first, to compare the prevalence of GERD symptoms and erosive esophagitis among patients with or without T2DM scheduled for bariatric surgery, hypothesizing a higher prevalence of GERD among patients with T2DM. Second, to assess whether erosive esophagitis was associated with GERD symptoms within both groups, and, third, to assess the associations between pathologic acid reflux, erosive esophagitis and GERD symptoms in patients with T2DM. 


\section{Materials and Methods}

\section{Trial design}

This is a cross sectional analysis of baseline data on GERD from the Oseberg study, an ongoing, randomized, triple-blind, single-center trial, which primarily aims to assess the effects of gastric bypass and sleeve gastrectomy on remission of T2DM $(23,24)$.

During the first year of this study, the prevalence of erosive esophagitis was higher than expected, and the potential impact of T2DM on these findings was unclear. Therefore, to explore whether the prevalence of GERD was particularly high among patients with T2DM, the steering committee decided, in 2014, to add a control group of bariatric patients without T2DM (23).

\section{Settings}

The study was conducted at the Morbid Obesity Centre at Vestfold Hospital Trust, a tertiary care obesity center in Southern Norway between January 2013 and February 2018.

\section{Participants}

All patients scheduled for bariatric surgery at the center were screened for study eligibility.

The inclusion criteria for both groups were age $\geq 18$ years, and BMI $\geq 35 \mathrm{~kg} / \mathrm{m}^{2}$, or BMI $\geq 33$ $\mathrm{kg} / \mathrm{m}^{2}$ with previously verified $\mathrm{BMI} \geq 35 \mathrm{~kg} / \mathrm{m}^{2}$.

T2DM was diagnosed in those with an $\mathrm{HbAlc} \geq 6.5 \%(48 \mathrm{mmol} / \mathrm{mol})$ or use of anti-diabetic medications. Exclusion criteria were previous major abdominal surgery, chronic medical conditions associated with increased risk of peri- and postoperative complications, drug or alcohol addiction, mental and psychiatric conditions leading to reduced compliance, pregnancy, and previously known severe gastro-esophageal reflux disease (Los Angeles classification grade C or D, or Barrett's esophagus). 


\section{Outcomes}

Prespecified secondary outcomes of the Oseberg study and the main outcomes of this analysis were GERD symptoms, erosive esophagitis and pathologic acid reflux.

\section{GERD symptom questionnaires}

The Gastroesophageal Reflux Disease Questionnaire (GerdQ) (25) is a validated 6-item questionnaire for reflux disease and includes four positive predictors for GERD; heartburn, regurgitation, sleep disturbances due to heartburn or reflux, and the use of over the counter medication, and two negative predictors for GERD; epigastric pain and nausea. The range of the total score for all six items is between 0-18. A validated Norwegian version of the questionnaire (26) was used. GerdQ was defined as positive when the score was $\geq 8$ points. The Gastrointestinal Symptom Rating Scale (GSRS) is a 15-item scale that assesses common symptoms of gastrointestinal disorders $(27,28)$. The GSRS - Reflux subscale includes two items; heartburn and acid regurgitation. Each item is scored from zero to six, where higher scores indicate greater severity of symptoms. The GSRS in European patient populations has a good internal consistency and reliability and acceptable construct validity and responsiveness $(27,28)$. The sum score was converted to a 0-100 scale to be comparable with other quality of life scales. GSRS-Reflux was defined as positive when the score was $\geq 20$ points.

\section{Erosive esophagitis}

Esophagogastroduodenoscopy (EGD) was performed by experienced endoscopists using Olympus $^{\circledR} 180$ or190 gastroscope. Anti-reflux medication was discontinued 7 days prior to EGD. Erosive esophagitis was graded according to the Los Angeles (LA) classification (29, 30) by two experienced endoscopists who were unaware of surgical procedure, based on the image of the lower esophageal sphincter (LES). In case of disagreement, the first author and the endoscopists reviewed the case together and reached an agreement. Hiatal hernia was 
measured longitudinally in centimeters from the LES to the diaphragmatic impression, and was defined as hiatal hernia if $\geq 2 \mathrm{~cm}$.

A diagnosis of Barrett's esophagus or adenocarcinoma was verified in biopsies. Non-erosive reflux disease (NERD) was defined as the presence of typical symptoms of GERD in the absence of visible esophageal mucosal injury on EGD and the presence of pathologic acid reflux (31).

\section{Ambulatory 24-hour pH-metry}

Ambulatory $\mathrm{pH}$-metry was performed after six hours fasting, and 7 days off proton pump inhibitor and $\mathrm{H} 2$ blocker, using the Digitrapper ${ }^{\mathrm{TM}} \mathrm{pH}-\mathrm{Z}$ Testing System, Medtronic, Minneapolis, USA.

The probe was introduced transnasally and placed $5 \mathrm{~cm}$ above LES after verification with high resolution manometry. Patients were asked to follow their normal daily habits, including eating habits, record upper GI symptoms, meals, medication, and supine position (bed time only). The data were recorded by a portable digital data logger for 24 hours, and DeMeester score was calculated using a standard software program (16). Pathologic acid reflux was diagnosed as DeMeester score $\geq 14.72$ (32) or distal esophageal acid exposure time (AET) $\geq$ $6 \%(11,16)$. The examination with 24 hour $\mathrm{pH}$-metry was preplanned and performed only in patients with T2DM.

Sample size

A total of 120 subjects with T2DM were planned to be included in the Oseberg study (23). To show a mean (SD) clinically meaningful difference of at least 10 (20) GSRS-score points between groups with or without T2DM (power $80 \%$ and alpha 0.05 ), at least 44 patients without T2DM had to be included. Taking into account possible loss to follow-up and incomplete data, a total of 64 controls without T2DM were included. 


\section{Blinding}

The patients, study staff, endoscopists and the primary outcome assessor, were blinded to treatment allocation, and the surgeons did not participate in the follow-up.

\section{Statistical methods}

Descriptive data are presented as mean (SD), median (range) or number (\%). Between-group comparisons were analyzed with independent samples t-test, and Chi-Square tests for continuous and categorical variables as appropriate. All tests were two-sided and $p$ values < 0.05 were considered statistically significant. All statistical analyses were performed using IBM SPSS 25 (SPSS Inc., Chicago, IL). 


\section{Results}

Between Oct 15, 2012, and Sept 1, 2017, 319 consecutive patients with T2DM were assessed for eligibility, 194 were excluded, and 125 patients were initially enrolled and underwent a baseline examination between Jan 28, 2013, and Feb 12, 2018 (Figure 1a). Further, one patient was excluded due to undetectable c-peptide level on baseline examination, leaving 124 patients to be included (Figure1a). A total of 210 consecutive patients without T2DM scheduled for bariatric surgery between January 2016 and January 2018, were assessed for eligibility, 81 patients were invited to participate, and 64 patients were included (Figure 1b).

Patients with T2DM were on average 6 years older than those without T2DM, and a lower proportion of patients with T2DM used non-steroidal anti-inflammatory drugs as compared with patients without T2DM (Table 1). Body mass index, drinking habits, smoking habits and the proportion of patients using anti-reflux medication did not differ significantly between groups (Table 1).

\section{GERD symptoms}

The GSRS and GerdQ questionnaires were completed by $97 \%$ of patients. The proportion of patients with reflux symptoms did not differ significantly between those with or without T2DM; GSRS, $28 \%$ versus $18 \%, p=0.12$, GerdQ, $14 \%$ versus $18 \%, p=0.53$ (Table 2 ).

\section{Esophagogastroduodenoscopy (EGD) findings}

With the exception of one patient with T2DM, all patients underwent EGD. The proportion of patients with esophagitis did not differ significantly between patients with or without T2DM, $58 \%$ versus $47 \%, p=0.16$ (Table 2 ). The majority of patients with findings had less advanced erosive esophagitis (Los Angeles grade A and B), and few patients had more advanced esophagitis (Los Angeles grade C (n=3) and D ( $n=2)$. Four patients with T2DM had Barrett's 
esophagus. Hiatal hernias were diagnosed in $44 \%$ of the patients in both groups (Table 2), and the majority of patients with hiatal hernia had erosive esophagitis, $36(67 \%)$ patients in the T2DM group and $23(82 \%)$ patients in the non-T2DM group.

\section{Association between erosive esophagitis and GERD symptoms}

GERD-symptoms were not significantly associated with erosive esophagitis among patients with or without T2DM (Table 3). Notably, the majority of patients with esophagitis did not have GERD-symptoms (68\%-80\%), while the majority of patients with GERD-symptoms had esophagitis (Table 3).Both questionnaires had low sensitivities (0.20-0.33) for diagnosing endoscopic esophagitis in both groups, while their respective specificities were higher $(0.76$ 0.94) (Table 4). Accordingly, the predictive values of negative tests were low in both groups, while the positive predictive value of GerdQ was relatively high (Table 4).

\section{4-hour pH-metry}

A total of 114 out of 124 (92\%) patients with T2DM completed the 24-hour $\mathrm{pH}$ monitoring out of whom 111 completed questionnaires and 113 underwent EGD. Pathologic acid reflux was diagnosed in 63 patients (55\%) with DeMeester score $\geq 14.72$ including 48 patients (42\%) with AET $\geq 6 \%$ (Table 5). Twenty of $65 \mathrm{~T} 2 \mathrm{DM}$ patients with erosive esophagitis did not have pathologic acid reflux (Table 5), but one of these patients had borderline GERD.

Further, 45 of 63 patients (71\%) with pathologic acid reflux had erosive esophagitis. In addition, 29 of 43 patients (67\%) who had both pathological acid reflux and erosive esophagitis, were asymptomatic. Three of the 18 patients (17\%) with GERD symptoms without erosive esophagitis had pathologic acid reflux (NERD). 


\section{Discussion}

The results from the present analysis of baseline data from the Oseberg study did not confirm our hypothesis of a higher prevalence of GERD among bariatric patients with T2DM compared with those without T2DM. Further, the proportions of patients with GERD symptoms were relatively low in both groups $(<29 \%)$, while approximately half the patients in both groups had esophagitis. In addition, in agreement with previous studies $(10,19,33)$, we found no significant association between GERD symptoms and erosive esophagitis in neither group. Notably, the majority of patients (both groups) with esophagitis did not have GERD-symptoms. In addition, more than half of the patients with T2DM had pathologic acid reflux, and the majority of these patients also had asymptomatic esophagitis.

\section{Possible mechanisms and explanations}

Taking into account that obesity and T2DM are independent predictors of GERD

$(9,14,34,35)$, we expected a higher prevalence of GERD-symptoms and esophagitis among patients with obesity and T2DM than in those with obesity only. T2DM may increase the risk of esophagitis due to reduced amplitude of esophageal contractions, fewer peristaltic waves, decreased velocity of peristalsis, reduced lower esophageal sphincter pressure and abnormal gastroesophageal reflux $(14,36-39)$. Notably, the numerical proportion of patients with esophagitis in the group with T2DM was higher than in the group without T2DM, but since sample size was calculated for differences in GSRS scores, we cannot rule out that the lack of statistical significance could be caused by a type 2 error.

The high prevalence of asymptomatic GERD (erosive esophagitis) in both groups might be partly explained by esophageal hyposensitivity due to obesity, diabetes or both (40). To our knowledge, the cause of esophageal hyposensitivity in patients with obesity and / or diabetes is unknown. However, it has been shown that in patients with Barrett's esophagus who often are hyposensitive to acid reflux, the nociceptive sensory nerves are located more profound in 
the esophageal mucosa (41). Accordingly, it can be speculated whether the subjects included in the present study may have deep sensory nerves, which may partly explain their esophageal hyposensitivity, but this was not assessed in the present study.

\section{Comparison with other studies}

To the best of our knowledge, our study is the first to compare the prevalence of GERD symptoms and erosive esophagitis among bariatric patients with or without T2DM. However, our finding of a low frequency of GERD symptoms confirms the results of previous studies of patients with morbid obesity $(33,35,42)$ and a study of patients with diabetes (43).

In addition, our results are in accordance with previous studies among bariatric surgery candidates which have documented a high prevalence of erosive esophagitis $(6,44)$

Our findings differ from the results in two previous studies which reported a high percentage of GERD symptoms among patients with morbid obesity $(5,45)$, but a low percentage of erosive esophagitis. However, these studies are not comparable with ours because they included younger patients and used self-reported gastrointestinal symptoms or other types of questionnaires than GerdQ and GSRS to assess GERD symptoms.

Our findings of a high prevalence of asymptomatic GERD in patients with and without T2DM, partly confirm previous studies, both from the general population and in populations with T2DM and /or obesity $(22,46)$. The association between GERD symptoms, as assessed by the validated questionnaires, and erosive esophagitis has been shown to be weak by others $(10,19,33)$. Our findings also support other studies demonstrating a poor association between GERD symptoms and pathologic acid reflux $(10,47)$, suggesting that most acid reflux events may be asymptomatic in patients with severe obesity. In line with the high frequency of asymptomatic esophagitis and acid reflux, only three patients had NERD in our study. Interestingly, 20 of 65 T2DM patients with erosive esophagitis did not have pathologic acid reflux, and only one of these had borderline GERD. This finding is in contrast with Kristo et 
al. (46), who reported a high proportion of borderline GERD among patients with esophagitis. In addition, duodeno-gastro-esophagal reflux of bile may partly explain our findings of erosive esophagitis in patients without acid reflux (48) but bile reflux was not assessed in the present study.

Our study has some limitations. Most patients were of Caucasian origin, with a majority of women (68\%), and the results may not be generalizable to other ethnicities. The comparative groups were non-matched, resulting in groups that differed in age and use of NSAIDs. Increasing age is risk factor for GERD, and older patients may underreport reflux symptoms (49).

\section{Conclusion}

Our results suggest that the prevalence of GERD in patients scheduled for bariatric surgery is similar in patients with or without T2DM, and that the proportion of patients with asymptomatic GERD is high independent of the presence or absence of diabetes. Accordingly, GERD may be underdiagnosed in patients not undergoing a preoperative endoscopy or acid reflux assessment. 


\section{Conflict of interest}

All authors declare that they have no conflict of interest.

\section{Ethical Approval Statement}

All procedures performed in studies involving human participants were in accordance with the ethical standards of the institutional and/or national research committee and with the 1964 Helsinki declaration and its later amendments or comparable ethical standards.

\section{Statement of informed consent}

Informed consent was obtained from all participants included in the study. 
Table 1 Demographic and clinical characteristics in candidates for bariatric surgery with or without type 2 diabetes mellitus (T2DM)

\begin{tabular}{|l|l|l|l|}
\hline & $\begin{array}{l}\text { T2DM } \\
(\mathrm{n}=124)\end{array}$ & $\begin{array}{l}\text { Non-T2DM } \\
(\mathrm{n}=64)\end{array}$ & $p$ value \\
\hline Age, years (SD) & $48.6(9.4)$ & $43.0(11.0)$ & $0.001^{\mathrm{a}}$ \\
\hline Gender, female, no. (\%) & $81(65)$ & $46(72)$ & $0.46^{\mathrm{b}}$ \\
\hline Ethnicity, Caucasian, no. (\%) & $117(96)$ & $64(100)$ & $0.24^{\mathrm{b}}$ \\
\hline Weight, kg (SD) & $125.6(21.8)$ & $127.2(20.1)$ & $0.63^{\mathrm{a}}$ \\
\hline Body mass index, BMI, kg/m ${ }^{2}(\mathrm{SD})$ & $42.3(5.5)$ & $43.0(5.0)$ & $0.46^{\mathrm{a}}$ \\
\hline Current smoker, no. (\%) & $14(11)$ & $4(6)$ & $0.34^{\mathrm{b}}$ \\
\hline Alcohol consumption (units per week) & $0(0-8)$ & $1(0-3)$ & $0.13^{\mathrm{b}}$ \\
\hline Use of anti-reflux medication, no. (\%) & $35(29)$ & $12(19)$ & $0.23^{\mathrm{b}}$ \\
\hline Proton pump inhibitors, no. (\%) & $14(11)$ & $20(32)$ & NA \\
\hline Diabetes complications, no. (\%)** & $13(12)$ & NA & $0.001^{\mathrm{b}}$ \\
\hline
\end{tabular}

Data are presented as observed mean (SD), median (range) or no. (\%) of patients

${ }^{\mathrm{a}}$ Independent samples t-test

${ }^{\mathrm{b}}$ Chi-Square test

* NSAID used due to self-reported co-morbidities like skeletal-muscle- and arthritisdisorders

** Retinopathy, neuropathy, or nephropathy (albuminuria) 
Table 2 GERD symptoms, endoscopic findings and 24-hour ambulatory pH-metry among bariatric candidates with or without type 2 diabetes mellitus (T2DM)

\begin{tabular}{|c|c|c|c|}
\hline & $\begin{array}{c}\text { T2DM } \\
(\mathrm{n}=123)\end{array}$ & $\begin{array}{c}\text { non-T2DM } \\
(\mathrm{n}=64)\end{array}$ & $p$ value \\
\hline GSRS-R-score $\geq 20$, no. $(\%)^{*}$ & $34(28)$ & $11(18)$ & $0.17^{\mathrm{b}}$ \\
\hline GerdQ-score $\geq 8$, no. $(\%)^{*}$ & $17(14)$ & $11(18)$ & $0.68^{\mathrm{b}}$ \\
\hline GSRS-R-score, mean (SD) * & $13.2(16.9)$ & $9.0(14.0)$ & $0.09^{a}$ \\
\hline GerdQ-score, mean (SD)* & $6.3(1.84)$ & $6.3(1.62)$ & $0.91^{\mathrm{a}}$ \\
\hline Esophagitis, no. (\%)** & $71(58)$ & $30(47)$ & $0.21^{\mathrm{b}}$ \\
\hline LA grade A, no. (\%) & $41(33)$ & $18(28)$ & \multirow{4}{*}{0.64} \\
\hline LA grade $\mathrm{B}$, no. $(\%)$ & $27(22)$ & $10(16)$ & \\
\hline LA grade $\mathrm{C}$, no. (\%) & $2(2)$ & 1(2) & \\
\hline LA grade $\mathrm{D}$, no. $(\%)$ & $1(0.8)$ & $1(1.6)$ & \\
\hline Barrett's esophagus, no. (\%) & $4(3)$ & 0 & 0.36 \\
\hline Hiatal hernia $\geq 2 \mathrm{~cm}$, no. $(\%)$ & $54(44)$ & $28(44)$ & $1.0^{\mathrm{b}}$ \\
\hline Hiatal hernia $\geq 5 \mathrm{~cm}$, no. $(\%)$ & $4(3)$ & 0 & $0.14^{\mathrm{b}}$ \\
\hline Peptic ulcer, no. (\%) & $7(6)$ & $8(13)$ & $0.18^{b}$ \\
\hline $\begin{array}{l}\text { DeMeester score, mean } \\
(\mathrm{SD}) * * *\end{array}$ & $24(22)$ & NA & NA \\
\hline $\begin{array}{l}\mathrm{pH}<4, \% \text { of time }(\mathrm{AET}) \\
(\mathrm{SD}) * * *\end{array}$ & $6.42(6.61)$ & NA & NA \\
\hline
\end{tabular}

Data are presented as observed mean (SD), or no. (\%) of patients

${ }^{a}$ Independent samples t-test

${ }^{\mathrm{b}}$ Chi-Square test

AET $=$ distal esophageal acid exposure time

* T2DM n=120, non-T2DM n=62

** $\quad \mathrm{T} 2 \mathrm{DM} \mathrm{n}=123$, non-T2DM $\mathrm{n}=64$

*** $\quad \mathrm{T} 2 \mathrm{DM} \mathrm{n}=114$ 
Table 3 Association between erosive esophagitis (any grade) and GERD symptoms among bariatric candidates with or without T2DM

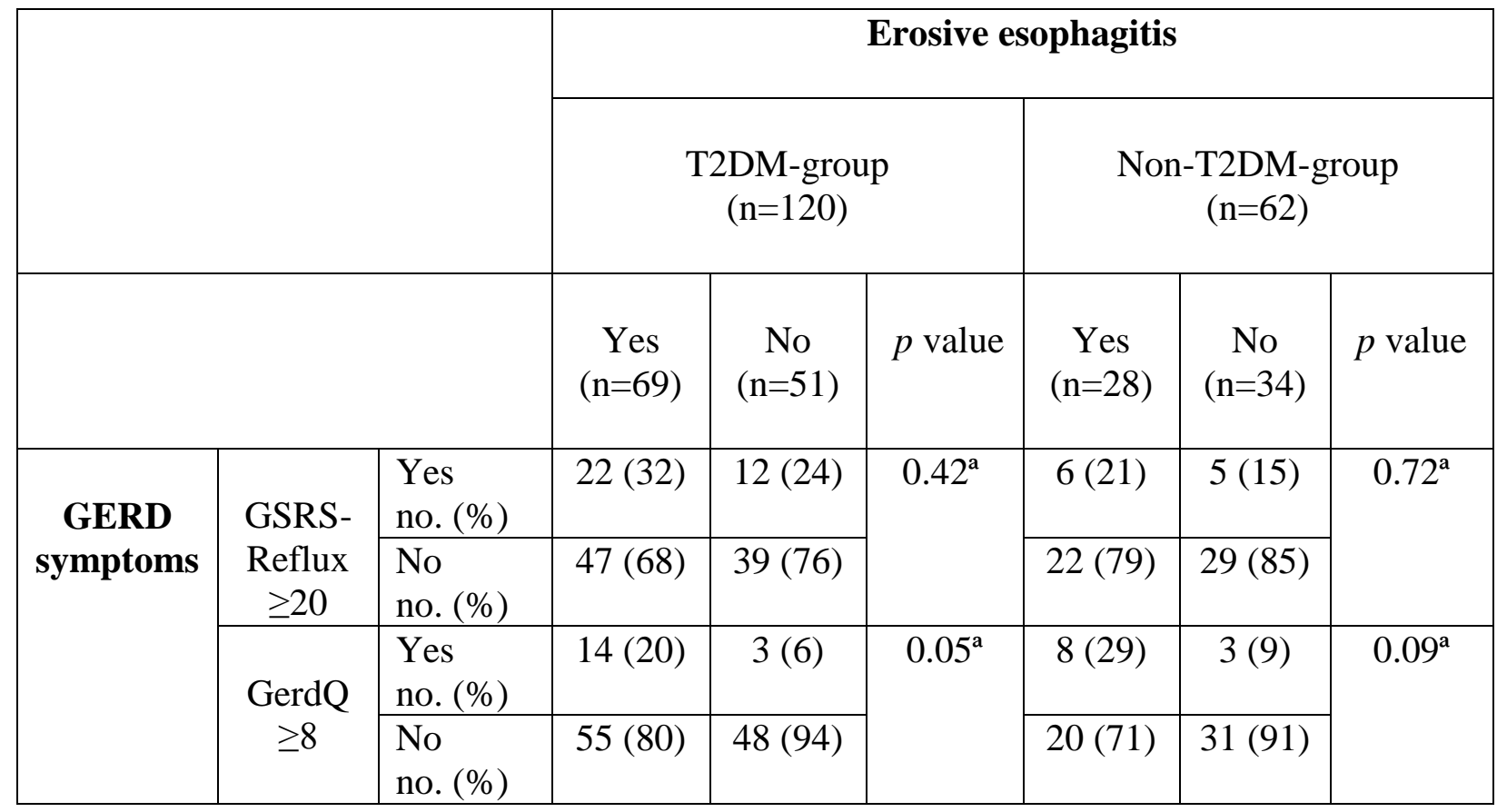

Data are presented as no. (\%) of patients

${ }^{\text {a }}$ Chi-Square test 
Table 4.

Sensitivity, specificity, positive predictive value and negative predictive value of GSRS $\geq 20$ and GerdQ $\geq 8$ for detection of endoscopic esophagitis among bariatric candidates with or without T2DM

\begin{tabular}{|l|c|c|c|c|}
\hline & \multicolumn{2}{|c|}{ GSRS-Reflux } & \multicolumn{2}{c|}{ GerdQ } \\
\hline & T2DM & non-T2DM & T2DM & non-T2DM \\
\hline Sensitivity & 0.33 & 0.21 & 0.20 & 0.28 \\
\hline Specificity & 0.76 & 0.85 & 0.94 & 0.91 \\
\hline Positive predictive value & 0.65 & 0.55 & 0.82 & 0.72 \\
\hline Negative predictive value & 0.45 & 0.57 & 0.46 & 0.60 \\
\hline
\end{tabular}


Table 5. Association between pathologic acid reflux, GERD symptoms and esophagitis among bariatric candidates with T2DM.

\begin{tabular}{|c|c|c|c|c|c|c|c|c|}
\hline & \multicolumn{3}{|c|}{$\begin{array}{l}\text { Pathological acid reflux } \\
\text { (DeMeester score) }\end{array}$} & \multicolumn{3}{|c|}{$\begin{array}{l}\text { Pathological acid reflux } \\
\text { (AET) }\end{array}$} \\
\hline & & & $\begin{array}{l}\text { No reflux } \\
(<14.72)\end{array}$ & $\begin{array}{l}\text { Reflux } \\
(\geq 14.72)\end{array}$ & $\begin{array}{l}p \\
\text { value }\end{array}$ & $\begin{array}{l}\text { No } \\
\text { reflux } \\
(<6 \%)\end{array}$ & $\begin{array}{l}\text { Reflux } \\
(\geq 6 \%)\end{array}$ & $\begin{array}{l}p \\
\text { value }\end{array}$ \\
\hline \multirow{5}{*}{$\begin{array}{l}\text { GERD } \\
\text { symptoms }\end{array}$} & \multirow{3}{*}{$\begin{array}{l}\text { GSRS- } \\
\text { Reflux } \\
\geq 20\end{array}$} & Total & 49 & 62 & & 64 & 47 & \\
\hline & & $\begin{array}{l}\text { Yes } \\
\mathrm{n}(\%)\end{array}$ & $13(27)$ & $19(31)$ & \multirow[t]{2}{*}{$0.79^{\mathrm{a}}$} & 17 (27) & $15(32)$ & \multirow[t]{2}{*}{$0.69^{\mathrm{a}}$} \\
\hline & & $\begin{array}{l}\text { No } \\
\mathrm{n}(\%)\end{array}$ & $36(73)$ & $43(69)$ & & 47 (73) & $32(68)$ & \\
\hline & \multirow[t]{2}{*}{$\begin{array}{l}\text { GerdQ } \\
\geq 8\end{array}$} & $\begin{array}{l}\text { Yes } \\
\mathrm{n}(\%)\end{array}$ & $5(10)$ & $10(16)$ & \multirow[t]{2}{*}{$0.53^{\mathrm{a}}$} & $7(11)$ & 8 (17) & \multirow[t]{2}{*}{$0.52^{\mathrm{a}}$} \\
\hline & & $\begin{array}{l}\text { No } \\
\mathrm{n}(\%)\end{array}$ & $44(90)$ & $52(84)$ & & 57 (89) & $39(83)$ & \\
\hline \multirow{3}{*}{$\begin{array}{l}\text { Erosive } \\
\text { esophagitis }\end{array}$} & & Total & 50 & 63 & & 65 & 48 & \\
\hline & & $\begin{array}{l}\text { Yes } \\
\text { n }(\%)\end{array}$ & $20(41)$ & $45(71)$ & \multirow[t]{2}{*}{$0.002^{\mathrm{a}}$} & $32(49)$ & $33(69)$ & \multirow[t]{2}{*}{$0.06^{\mathrm{a}}$} \\
\hline & & $\begin{array}{l}\text { No } \\
\mathrm{n}(\%)\end{array}$ & $30(59)$ & $18(29)$ & & $33(51)$ & $15(31)$ & \\
\hline
\end{tabular}

Data are presented as number (\%) of patients

AET $=$ distal esophageal acid exposure time

${ }^{\text {a }}$ Chi-Square test 


\section{References}

1. Katz PO, Gerson LB, Vela MF. Guidelines for the diagnosis and management of gastroesophageal reflux disease. The American journal of gastroenterology. 2013;108(3):30828; quiz 29.

2. Punjabi P, Hira A, Prasad S, Wang X, Chokhavatia S. Review of gastroesophageal reflux disease (GERD) in the diabetic patient. Journal of diabetes. 2015;7(5):599-609.

3. Gyawali CP, de Bortoli N, Clarke J, Marinelli C, Tolone S, Roman S, et al. Indications and interpretation of esophageal function testing. Annals of the New York Academy of Sciences. 2018;1434(1):239-53.

4. El-Serag HB, Sweet S, Winchester CC, Dent J. Update on the epidemiology of gastrooesophageal reflux disease: a systematic review. Gut. 2014;63(6):871-80.

5. Merrouche M, Sabate JM, Jouet P, Harnois F, Scaringi S, Coffin B, et al. Gastroesophageal reflux and esophageal motility disorders in morbidly obese patients before and after bariatric surgery. Obes Surg. 2007;17(7):894-900.

6. Bou Daher H, Sharara AI. Gastroesophageal reflux disease, obesity and laparoscopic sleeve gastrectomy: The burning questions. World journal of gastroenterology. 2019;25(33):4805-13.

7. Savarino E, Bredenoord AJ, Fox M, Pandolfino JE, Roman S, Gyawali CP. Expert consensus document: Advances in the physiological assessment and diagnosis of GERD. Nature reviews Gastroenterology \& hepatology. 2017;14(11):665-76.

8. Dulai GS, Guha S, Kahn KL, Gornbein J, Weinstein WM. Preoperative prevalence of Barrett's esophagus in esophageal adenocarcinoma: a systematic review. Gastroenterology. 2002;122(1):26-33.

9. Anggiansah R, Sweis R, Anggiansah A, Wong T, Cooper D, Fox M. The effects of obesity on oesophageal function, acid exposure and the symptoms of gastro-oesophageal reflux disease. Alimentary pharmacology \& therapeutics. 2013;37(5):555-63.

10. Heimgartner B, Herzig M, Borbely Y, Kroll D, Nett P, Tutuian R. Symptoms, endoscopic findings and reflux monitoring results in candidates for bariatric surgery.

Digestive and liver disease : official journal of the Italian Society of Gastroenterology and the Italian Association for the Study of the Liver. 2017;49(7):750-6.

11. Wilson LJ, Ma W, Hirschowitz BI. Association of obesity with hiatal hernia and esophagitis. The American journal of gastroenterology. 1999;94(10):2840-4.

12. Pandolfino JE, El-Serag HB, Zhang Q, Shah N, Ghosh SK, Kahrilas PJ. Obesity: a challenge to esophagogastric junction integrity. Gastroenterology. 2006;130(3):639-49.

13. Iyer PG, Borah BJ, Heien HC, Das A, Cooper GS, Chak A. Association of Barrett's esophagus with type II Diabetes Mellitus: results from a large population-based case-control study. Clinical gastroenterology and hepatology : the official clinical practice journal of the American Gastroenterological Association. 2013;11(9):1108-14.e5.

14. Sun XM, Tan JC, Zhu Y, Lin L. Association between diabetes mellitus and gastroesophageal reflux disease: A meta-analysis. World journal of gastroenterology. 2015;21(10):3085-92.

15. Horikawa A, Ishii-Nozawa R, Ohguro M, Takagi S, Ohtuji M, Yamada M, et al. Prevalence of GORD (gastro-oesophageal reflux disease) in Type 2 diabetes and a comparison of clinical profiles between diabetic patients with and without GORD. Diabetic medicine : a journal of the British Diabetic Association. 2009;26(3):228-33.

16. Gyawali CP, Kahrilas PJ, Savarino E, Zerbib F, Mion F, Smout A, et al. Modern diagnosis of GERD: the Lyon Consensus. Gut. 2018;67(7):1351-62. 
17. Mainie I, Tutuian R, Shay S, Vela M, Zhang X, Sifrim D, et al. Acid and non-acid reflux in patients with persistent symptoms despite acid suppressive therapy: a multicentre study using combined ambulatory impedance-pH monitoring. Gut. 2006;55(10):1398-402. 18. Stanghellini V, Armstrong D, Monnikes H, Bardhan KD. Systematic review: do we need a new gastro-oesophageal reflux disease questionnaire? Alimentary pharmacology \& therapeutics. 2004;19(5):463-79.

19. Sakitani K, Suzuki N, Ihara S, Hirata Y, Kawazu S, Iwamoto Y, et al. Decline in perception of acid regurgitation symptoms from gastroesophageal reflux disease in diabetes mellitus patients. PloS one. 2018;13(3):e0194466.

20. Madalosso CA, Fornari F, Callegari-Jacques SM, Madalosso CA, Gurski RR.

Performance of the Montreal Consensus in the diagnosis of gastroesophageal reflux disease in morbidly obese patients. Obes Surg. 2008;18(6):668-74.

21. Ronkainen J, Aro P, Storskrubb T, Johansson SE, Lind T, Bolling-Sternevald E, et al. High prevalence of gastroesophageal reflux symptoms and esophagitis with or without symptoms in the general adult Swedish population: a Kalixanda study report. Scandinavian journal of gastroenterology. 2005;40(3):275-85.

22. Ortiz V, Ponce M, Fernandez A, Martinez B, Ponce JL, Garrigues V, et al. Value of heartburn for diagnosing gastroesophageal reflux disease in severely obese patients. Obesity (Silver Spring, Md). 2006;14(4):696-700.

23. Borgeraas H, Hjelmesaeth J, Birkeland KI, Fatima F, Grimnes JO, Gulseth HL, et al. Single-centre, triple-blinded, randomised, 1-year, parallel-group, superiority study to compare the effects of Roux-en-Y gastric bypass and sleeve gastrectomy on remission of type 2 diabetes and beta-cell function in subjects with morbid obesity: a protocol for the Obesity surgery in Tonsberg (Oseberg) study. BMJ open. 2019;9(6):e024573.

24. Hofso D, Fatima F, Borgeraas H, Birkeland KI, Gulseth HL, Hertel JK, et al. Gastric bypass versus sleeve gastrectomy in patients with type 2 diabetes (Oseberg): a single-centre, triple-blind, randomised controlled trial. The lancet Diabetes \& endocrinology. 2019;7(12):912-24.

25. Jonasson C, Wernersson B, Hoff DA, Hatlebakk JG. Validation of the GerdQ questionnaire for the diagnosis of gastro-oesophageal reflux disease. Alimentary pharmacology \& therapeutics. 2013;37(5):564-72.

26. Jonasson C, Moum B, Bang C, Andersen KR, Hatlebakk JG. Randomised clinical trial: a comparison between a GerdQ-based algorithm and an endoscopy-based approach for the diagnosis and initial treatment of GERD. Alimentary pharmacology \& therapeutics. 2012;35(11):1290-300.

27. Dimenas E, Glise H, Hallerback B, Hernqvist H, Svedlund J, Wiklund I. Well-being and gastrointestinal symptoms among patients referred to endoscopy owing to suspected duodenal ulcer. Scandinavian journal of gastroenterology. 1995;30(11):1046-52.

28. Revicki DA, Wood M, Wiklund I, Crawley J. Reliability and validity of the Gastrointestinal Symptom Rating Scale in patients with gastroesophageal reflux disease. Quality of life research : an international journal of quality of life aspects of treatment, care and rehabilitation. 1998;7(1):75-83.

29. Vakil N, van Zanten SV, Kahrilas P, Dent J, Jones R. The Montreal definition and classification of gastroesophageal reflux disease: a global evidence-based consensus. The American journal of gastroenterology. 2006;101(8):1900-20; quiz 43.

30. Lundell LR, Dent J, Bennett JR, Blum AL, Armstrong D, Galmiche JP, et al. Endoscopic assessment of oesophagitis: clinical and functional correlates and further validation of the Los Angeles classification. Gut. 1999;45(2):172-80.

31. Savarino E, Zentilin P, Savarino V. NERD: an umbrella term including heterogeneous subpopulations. Nature reviews Gastroenterology \& hepatology. 2013;10(6):371-80. 
32. Liu S, Xu M, Yang J, Qi H, He F, Zhao X, et al. Research on Gastroesophageal Reflux Disease Based on Dynamic Features of Ambulatory 24-Hour Esophageal pH Monitoring. Computational and mathematical methods in medicine. 2017;2017:9239074.

33. Sharaf RN, Weinshel EH, Bini EJ, Rosenberg J, Sherman A, Ren CJ. Endoscopy plays an important preoperative role in bariatric surgery. Obes Surg. 2004;14(10):1367-72.

34. Argyrou A, Legaki E, Koutserimpas C, Gazouli M, Papaconstantinou I, Gkiokas G, et al. Risk factors for gastroesophageal reflux disease and analysis of genetic contributors.

World journal of clinical cases. 2018;6(8):176-82.

35. El-Serag H. Role of obesity in GORD-related disorders. Gut. 2008;57(3):281-4.

36. Wang X, Pitchumoni CS, Chandrarana K, Shah N. Increased prevalence of symptoms of gastroesophageal reflux diseases in type 2 diabetics with neuropathy. World journal of gastroenterology. 2008;14(5):709-12.

37. Lee SD, Keum B, Chun HJ, Bak YT. Gastroesophageal Reflux Disease in Type II Diabetes Mellitus With or Without Peripheral Neuropathy. Journal of neurogastroenterology and motility. 2011;17(3):274-8.

38. Gatopoulou A, Papanas N, Maltezos E. Diabetic gastrointestinal autonomic neuropathy: current status and new achievements for everyday clinical practice. European journal of internal medicine. 2012;23(6):499-505.

39. Krishnan B, Babu S, Walker J, Walker AB, Pappachan JM. Gastrointestinal complications of diabetes mellitus. World journal of diabetes. 2013;4(3):51-63.

40. Frokjaer JB, Andersen SD, Ejskaer N, Funch-Jensen P, Arendt-Nielsen L, Gregersen H, et al. Gut sensations in diabetic autonomic neuropathy. Pain. 2007;131(3):320-9.

41. Woodland P, Shen Ooi JL, Grassi F, Nikaki K, Lee C, Evans JA, et al. Superficial Esophageal Mucosal Afferent Nerves May Contribute to Reflux Hypersensitivity in Nonerosive Reflux Disease. Gastroenterology. 2017;153(5):1230-9.

42. Suter M, Dorta G, Giusti V, Calmes JM. Gastro-esophageal reflux and esophageal motility disorders in morbidly obese patients. Obes Surg. 2004;14(7):959-66.

43. Kase H, Hattori Y, Sato N, Banba N, Kasai K. Symptoms of gastroesophageal reflux in diabetes patients. Diabetes research and clinical practice. 2008;79(2):e6-7.

44. Mora F, Cassinello N, Mora M, Bosca M, Minguez M, Ortega J. Esophageal abnormalities in morbidly obese adult patients. Surgery for obesity and related diseases : official journal of the American Society for Bariatric Surgery. 2016;12(3):622-8.

45. Tolone S, Limongelli P, del Genio G, Brusciano L, Rossetti G, Amoroso V, et al. Gastroesophageal reflux disease and obesity: do we need to perform reflux testing in all candidates to bariatric surgery? International journal of surgery (London, England). 2014;12 Suppl 1:S173-7.

46. Kristo I, Paireder M, Jomrich G, Felsenreich DM, Nikolic M, Langer FB, et al. Modern Esophageal Function Testing and Gastroesophageal Reflux Disease in Morbidly Obese Patients. Obes Surg. 2019;29(11):3536-41.

47. Gokturk S, Akyuz F, Arici S, Alpaslan B, Ormeci A, Soyer OM, et al. Gastroesophageal Reflux in Asymptomatic Patients with Diabetes: An Impedance Study Diabetes, Obesity and Gastroesophageal Reflux. Experimental and clinical endocrinology \& diabetes : official journal, German Society of Endocrinology [and] German Diabetes Association. 2018.

48. Tack J, Koek G, Demedts I, Sifrim D, Janssens J. Gastroesophageal reflux disease poorly responsive to single-dose proton pump inhibitors in patients without Barrett's esophagus: acid reflux, bile reflux, or both? The American journal of gastroenterology. 2004;99(6):981-8. 
49. Johnson DA, Fennerty MB. Heartburn severity underestimates erosive esophagitis severity in elderly patients with gastroesophageal reflux disease. Gastroenterology.

2004;126(3):660-4. 